\title{
UJI COBA APLIKASI PEMANENAN AIR HUJAN DAN SUMUR RESAPAN DI WILAYAH BOGOR, DEPOK DAN JAKARTA
}

\author{
Arie Herlambang, R. Haryoto Indriatmoko, Satmoko Yudo dan Samsuhadi.
}

Pusat Teknologi Lingkungan, BPPTeknologi

JI. MH. Thamrin No. 8 Jakarta Pusat

\begin{abstract}
Areas of Jakarta, Bogor, Tangerang and Bekasi (Greater Jakarta) is an area with high rainfall (2250 -2500 mm/year). The rain that falls in this region often cause flooding problems in the area of rice fields, settlements and even in downtown. Rain is a gift from God to be utilized to the maximum extent possible for everyday purposes. Rain Water Harvesting is an attempt to capture rainwater that falls on the roof. In this study, use of the roof area of about $300-500 \mathrm{~m}^{2}$. Precipitation that falls on the roof is channeled and put into storage, by first filtering done to reduce the dirt. The volume of rain water storage for each location is $10 \mathrm{~m}^{3}$, medium intensity rain $(15-20 \mathrm{~mm} / \mathrm{h})$, sufficient to meet the storage within a few hours. Rain Water Reservoir are equipped with water pump which has a capacity of 25 liters/minute, the water can be used for flushing toilets and spraying crops. If Rain Water Reservoir is full, water overflows into the Artificial recharge well. The results of analysis with Kostiokov calculation method used to calculate the infiltration rate of Artificial recharge well and calculate the cumulative volume of infiltration at the Artificial recharge well. Results of tests conducted are as follows: a). In Depok, the infiltration rate of Artificial Recharge Well is about $12 \mathrm{~mm} /$ minute and was relatively stable at 140 minute (2 $\mathrm{mm} /$ minute). It also has the ability to recharge 450 liters of water in 140 minutes. b). In South Jakarta, the infiltration rate of Artificial Recharge Well is about $11 \mathrm{~mm} /$ minute and was relatively stable at 160 minutes $(2.5 \mathrm{~mm} /$ minute). Artificial Recharge Well has the ability to recharge 480 liters of water in 160 minutes. c). In Bantarjati, Bogor, Artificial Recharge Well have the highest capacity, namely $45 \mathrm{~mm} /$ minute and was relatively stable at 260 minutes $(2.5 \mathrm{~mm} /$ minute). Artificial Recharge Well has the ability to recharge 1000 liters of water in 150 minutes. Rain Water Harvesting Development Efforts and Artificial Recharge Well very useful to overcome inundation in residential areas, especially during heavy rain, because it can reduce the volume of surface water into the channel simultaneously.
\end{abstract}

Keywords : Rain Water Harvesting, Infiltration, Artificial Recharge.

\section{PENDAHULUAN}

\subsection{Latar Belakang}

Hujan merupakan fenomena alam yang terjadi di suatu wilayah. Kehadirannya dalam skala lokal terkait dengan siklus hidrologi dan secara regional terkait dengan iklim global. Air hujan sangat bermanfaat untuk mengisi sumber air guna keperluan pertanian, domestik dan industri, namun air hujan yang tidak dikelola dapat juga menimbulkan bencana seperti banjir dan genangan.

Pemanenan Air Hujan (PAH) merupakan salah satu upaya masyarakat untuk memanfaatkan air hujan guna keperluan sehari-hari. Di Indonesia PAH banyak dibangun di wilayah pesisir dan pulau-pulau kecil yang sering mengalami kekurangan air, namun dengan banyaknya kejadian banjir dan genangan yang sering menimpa wilayah padat pemukiman, maka diperlukan upaya tambahan untuk membuat $\mathrm{PAH}$ dan Sumur Resapan (SURES).
Prinsip dasar $\mathrm{PAH}$ adalah mengalirkan air hujan yang jatuh di permukaan atap melalui talang air untuk ditampung ke dalam tangki penampung. Kemudian limpasan air yang keluar dari tangki penampung yang telah penuh disalurkan ke dalam sumur resapan. Budaya pembuatan PAH dan SURES ini sudah banyak dilakukan di banyak negara. Secara teknologi, PAH dan SURES bukan merupakan teknologi yang sulit, bahan dan pembangunannya dapat dilakukan oleh masyarakat sendiri,

Jika budaya memanen air hujan dan meresapkan limpahan air ke dalam tanah ini dimasyarakatkan, maka akan didapat sejumlah besar keuntungan, antara lain: sumber air bersih yang murah, penambahan jumlah cadangan air tanah dan pengurangan limpasan yang dapat menghindarkan suatu wilayah dari genangan dan banjir.

Ide PAH dan SURES ini dilatar belakangi dari masalah umum yang terjadi diberbagai wilayah di Indonesia, terutama DKI Jakarta dan sekitarnya, yaitu kekurangan air bersih, 
penyusutan cadangan air tanah, genangan, banjir musiman dan masuknya intrusi air laut ke dalam sistem akuifer. Ide ini sekaligus mendukung Implementasi Pelestarian Sumberdaya Air dalam UU No.7 tentang Sumberdaya Air(6) dan upaya Pemerintah DKI Jakarta tentang kewajiban pembuatan sumur resapan seperti yang ditetapkan dalam Peraturan Gubernur DKI No 115 Tahun 2001 tentang Pembuatan Sumur Resapan(3) dan revisinya No. 68 Tahun $2005^{(4)}$.

\subsection{Tujuan Dan Sasaran}

untuk :

Uji coba PAH dan SURES ini bertujuan

a) Mengurangi volume air yang mengalir dipermukaan pada saat hujan lebat pada lokasi rawan banjir dan genangan.

b) Restorasi sumber daya air tanah melalui peningkatan sumur resapan buatan secara gravitasi dengan menggunakan sumur resapan.

c) Sosialisasi cara Pemanenan Air Hujan dan Sumur Resapan melalui dunia pendidikan.

Sedangkan sasaran dari uji coba ini adalah :

a) Mendapatkan laju infiltrasi lapisan tanah/ batuan di lokasi uji coba.

b) Mendapatkan volume kumulatif yang dapat diresapkan dalam setiap waktu sesaat setelah hujan.

\subsection{Waktu Dan Lokasi}

Persiapan, pembangunan dan ujicoba ini dilakukan selama Bulan Juli sampai dengan November 2010, dengan Lokasi Penelitian adalah Sekolah Dasar Kawung Luwuk, Bantarjati, Bogor Utara, SMAN 4, Depok dan SMA AL Azhar, Jakarta Timur.

\section{METODOLOGI}

Metodologi yang digunakan dalam kegiatan ini ada 3 tahapan yaitu :

\subsection{Pemanenan Air Hujan (PAH)}

a. Penentuan lokasi dengan curah hujan tinggi (> $2000 \mathrm{~mm} /$ tahun).

b. Terdapat bangunan dengan luas atap berkisar $300-500 \mathrm{~m}^{2}$.

c. Volume PAH ditentukan $10 \mathrm{~m}^{3}$, oleh karena itu dipilih tempat atau wilayah yang sering tergenang atau pada saat hujan air meluap dari salurannya dan mempunyai tempat yang memungkinkan untuk dilakukan konstruksi, dengan luas area kerja sekitar $3 \times 10$ meter. Kedalaman penggalian sampai 3 meter, konstruksi dengan menggunakan beton bertulang, dan bangunan tertutup.

d. Prinsip kerja : air dari atap bangunan dikumpukan dengan menggunakan talang, disalurkan menuju PAH. Sebelum masuk ke dalam bak penampungan, air disaring dengan pasir kasar pada bak pertama, untuk menyaring kotoran dari atap bangunan. Air yang dimanfaatkan adalah air dari bak kedua.

e. Pemanfaatan air dengan cara dipompa dan sebelum digunakan disaring dahulu dengan media pasir halus dan karbon aktif.

f. Pengujian dilakukan selama musim hujan, untuk mengukur kecepatan pengisian dan kualitas air serta pemanfaatannya.

\subsection{Sumur Resapan (SURES)}

a. Sumur resapan digunakan untuk menampung limpahan air yang keluar dari $\mathrm{PAH}$ yang telah penuh.

b. Air dari $\mathrm{PAH}$ masuk ke sumur resapan dengan menggunakan pipa PVC diameter 4 inchi, sepanjang 2 meter.

c. Kedalaman sumur resapan adalah $3 \mathrm{~m}$, dengan panjang bidang resapan $0,5 \mathrm{~m}$ dan diameter sumur $1 \mathrm{~m}$.

d. Pengujian resapan dilakukan secara langsung dengan mengisi sumur resapan dengan menggunakan mobil tangki air atau tidak langsung dengan pengujian menggunakan infiltrometer.

e. Pengukuran penurunan permukaan air dilakukan setiap 5 menit sekali.

f. Informasi tersebut digunakan untuk mengukur kecepatan infiltrasi dan mengukur banyaknya volume air yang masuk untuk setiap satuan waktu, pada masing-masing sumur resapan yang diukur.

\subsection{Metode Analisis Data}

Data pengukuran infiltrasi tersebut kemudian diolah untuk mendapatkan informasi tentang laju infiltrasi dalam sumur resapan dan ring-infiltrometer. Pengolahan data dilakukan dengan tahap sebagai berikut:

a. Catat data penurunan muka air pada setiap waktu interval 5 (lima) menit.

b. Buat grafik hubungan antara kumulatif dari waktu pengukuran (menit) dengan kumulatif penurunan muka air (cm).

c. Akumulasi infiltrasi adalah total jumlah air yang masuk ke dalam tanah pada selang waktu tertentu. Rumus dari akumulasi infiltrasi(14) adalah: $\mathbf{F}=\mathbf{k} \mathbf{t}^{\mathbf{n}}$

d. Dengan menggunakan Software Microsoft Excel lakukan analisis trendline untuk mendapatkan rumus persamaan dan 
koefisien regresinya dengan menggunakan tool Trend/Regression Type dan sajikan rumus persamaam dan koefisien regresinya kedalam grafik.

e. Untuk menghitung besarnya laju infiltrasi, persamaan laju infiltrasi dideferensialkan, sehingga rumus menjadi(14) :

I = dF/dt = knt ${ }^{\text {n-1. }}$.

f. Rumus laju infiltrasi yang sudah didapat dari deferensial dari $\mathrm{dF} / \mathrm{dt}$ digunakan membuat tabel hubungan antara kumulatif waktu (t) dengan I.

g. Buat grafik hubungan antara t dengan I, kemudian tarik garis laju infiltrasi pada garis konstan untuk mendapatkan besarnya laju infiltrasi pada percobaan menggunakan ring infiltrometer ( $\mathrm{mm} / \mathrm{menit}$ ) atau laju volume peresapan pada sumur resapan (liter/menit)

\section{PERALATAN DAN BAHAN}

Uji coba ini membutuhkan peralatan pendukung :

1. PAH beserta sistem pengumpulan air dan sistem pemanfaatannya.

2. SURES yang masih baru dan belum pernah beroperasi.

3. Pengukur curah hujan dan lama hujan.

4. Pengukur ketinggian muka air.

5. Pompa dan saringan air serta selang air.

6. Sistem kelistrikan.

7. Form pencatatan

Spesifikasi PAH sebagai berikut :

$\begin{array}{ll}\text { 1. Lebar } & : 2,1 \mathrm{~m} \\ \text { 2. Panjang } & : 3,0 \mathrm{~m} \\ \text { 3. Kedalaman } & : 2,5 \mathrm{~m} \\ \text { 4. Luas Bak Penyaring } & : 1,0 \mathrm{~m}^{3} \\ \text { 5. Volume Resapan } & : 10 \mathrm{~m}^{3} \\ \text { 6. Panjang Talang } & : 75 \mathrm{~m} \\ \text { 7. Luas Atap Rumah } & : 375 \mathrm{~m} \\ \text { 8. Kemiringan Atap } & : 35 \circ \\ \text { 9. Tinggi Jatuhan Air } & : 3 \mathrm{~m} \\ \text { 10. Pompa Air } & : 25 \mathrm{l} / \mathrm{m} \\ \text { 11. Saringan Pasir/Karbon } & : 1,0 \mathrm{~m}\end{array}$

Spesifikasi SURES sebagai berikut :
1. Diameter Pipa Inlet
: 4,0 In
2. Kedalaman Total
: $3,0 \mathrm{~m}$
3. Diameter
: $1,0 \mathrm{~m}$
4. Tebal Dinding
$: 0,1 \mathrm{~m}$
5. Tebal Bidang Resapan : $: 1,0 \mathrm{~m}$
6. Diameter Resapan :1,0 m

Untuk jelasnya lihat Gambar 1 dan 2.

Untuk uji coba kemampuan resapan sumur digunakan pengujian langsung dengan mengisi sumur resapan yang ada, dengan menggunakan mobil tangki dan mengukur laju penurunan airnya, sedangkan untuk pengukuran tidak langsung dilakukan dengan mengukur laju infiltrasi dari tanah disekitar sumur resapan, dengan menggunakan alat infiltrometer (Gambar 3).

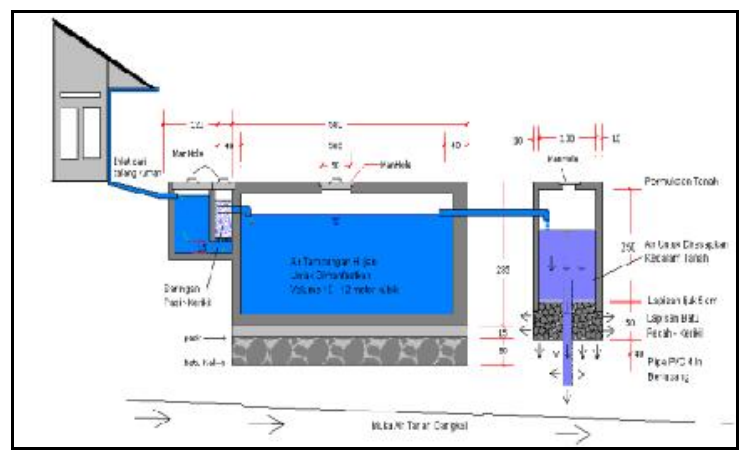

Gambar 1. Disain PAH dan SURES (Tampak Samping)

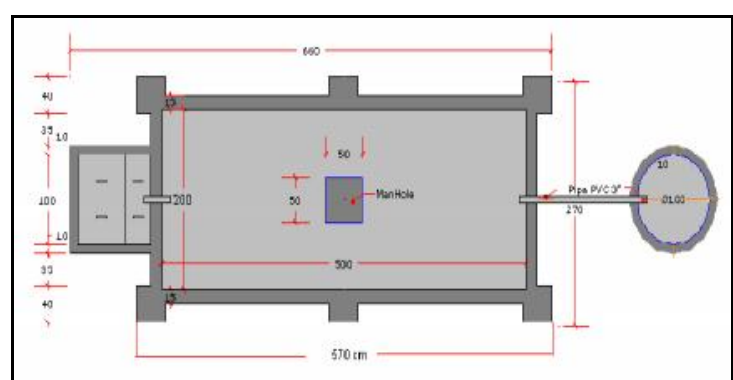

Gambar 2. Desain PAH dan SURES (Tampak atas)

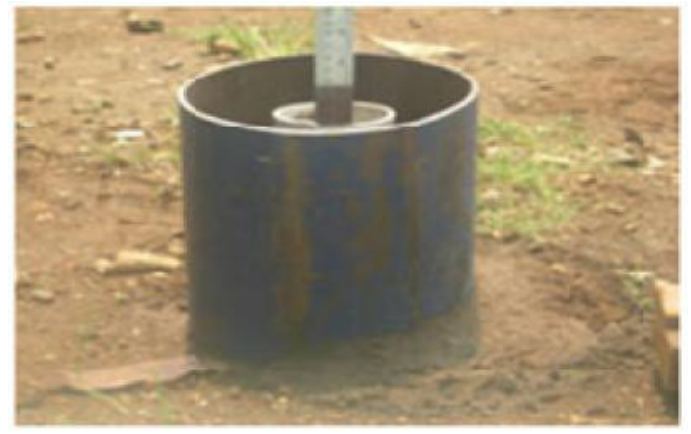

Gambar 3. Alat Ukur Infiltrometer Sederhana Yang Digunakan Untuk Mengukur Laju Peresapan Pada Tanah Di Sekitar Sumur Resapan

\section{TINJAUAN PUSTAKA}

\subsection{Hidrologi dan Geohidrologi Jakarta}

Inventarisasi sumur dilakukan, yang terdiri atas 300 buah sumur yang tersebar di daerah Jakarta, Bekasi dan Tangerang. Pengukuran konduktivitas listrik dan dalam muka air tanah telah dilakukan selama musim kering pada tahun 1983 dan musim hujan tahun 1984. 
Dari hasil pengukuran tersebut diperkirakan bahwa pengisian akuifer terjadi sebesar 518 hingga 785 juta $\mathrm{m}^{3} /$ tahun. Besaran perkiraan ini dapat dijadikan gambaran umum kemampuan imbuhan alam yang terjadi pada akuifer dangkal(5).

Kebanyakan dari data hidrogeologi didasarkan atas hasil penyelidikan yang dilakukan oleh DEG, HAG dan Sukardi(5,7,10), terutama untuk geologi dan muka air yang di dalam skemanya diindikasikan tiga lapis akuifer. Data pengambilan air tanah didapat dari DEG dan PAM Jaya. Pengisian (recharge) diestimasikan dengan menghitung neraca air untuk beberapa area. Tinggi muka air tanah, zona storage tak jenuh, aliran sungai dan evapotranspirasi ditentukan sementara pengisian akuifer dihitung sebagai sisanya. Kemudiann simulasi model komputer dengan tiga akuifer dilakukan. Antara pertengahan dan Pleistocene bawah diasumsikan terdapat lapisan kedap air (confining bed). Kalibrasi model terdiri atas penyesuaian karakteristik akuifer dan besaran pengambilan air tanah hingga cocok dengan data air tanah dari tahun 1970-1985. Hasil simulasi memperlihatkan bahwa pengambilan air tanah pada tahun-tahun setelahnya terlihat lebih besar daripada perkiraan ${ }^{(14,15,17)}$.

Pusat Teknologi Sumber Daya Air, Departemen Pemukiman dan Prasarana Wilayah, 2000, melakukan Studi Banjir di Wilayah Kamal - Cengkareng - Kapuk. Sesuai dengan pengamatan lapangan dan analisis geoteknik kondisi tanah setempat, terdapat hubungan antara pemanfaatan air tanah yang berlebihan dan melewati daya dukung akuifer(5). Diketahui bahwa di kawasan Jakarta Barat sebelah utara di sekitar Batu Ceper, penurunan muka air tanah hingga $44 \mathrm{~m}$ di bawah muka air laut, sedangkan di Jakarta Timur di sekitar kawasan Pulo Gadung tinggi muka air tanah turun hingga $16 \mathrm{~m}$ di bawah muka air laut dengan penurunan muka tanah hingga $180 \mathrm{~cm}$ selama periode tahun $1982-1997^{(8)}$ di kawasan Jakarta Barat. Dari studi ini disarankan ada tiga jenis daerah konservasi air tanah yang disebut daerah kritis, rawan dan aman.

Sebagian warga Jakarta dan sekitarnya memanfaatkan air tanah guna memenuhi kebutuhan air minumnya(10). Hal ini dilakukan karena sumber utama air minum yang seharusnya disediakan oleh PDAM tidak dapat diperoleh secara maksimal. Dengan kemampuan pasokan sebesar 235 juta $\mathrm{m}^{3}$ pada tahun 2003 (PDAM JAYA), sedangkan kebutuhan air bersih total di DKI Jakarta diperkirakan 612 juta $\mathrm{m}^{3}$ pada tahun yang sama, maka kemampuan PDAM hanya dapat memenuhi kebutuhan air bersih sekitar $38 \%$ dari kebutuhan total. Oleh karena itu sebagian masyarakat (yang tidak mempunyai akses ke PDAM) mengambil air tanah sebagai pengganti pasokan air bersih dari PDAM.

Pemakaian air tanah di Jabodetabek sudah sangat tinggi dan mengindikasikan bahwa volume pengambilan air tanah ini sudah melebihi kemampuan pengisiannya. Hal ini terindikasi dari intensifnya ekstraksi air tanah Jakarta, yaitu sekitar 1000 juta $\mathrm{m}^{3}$ pada tahun $1992^{(5)}$. Potensi air tanah Jakarta diperkirakan sebesar 840 juta $\mathrm{m}^{3}$, sehingga jika dibandingkan dengan tingkat ekstraksi, maka terdapat defisit yang signifikan.

Terjadinya peningkatan daerah genangan dan banjir di beberapa kawasan dalam kota Jakarta dan sekitarnya mengindikasikan semakin turunnya permukaan tanah di wilayah DKI. Perambatan atau peningkatan insiden penurunan muka tanah ini terasa semakin memburuk, baik kedalaman maupun luas area yang terkena penurunan muka tanah tersebut. Insiden turunnya muka tanah ini adalah salah satu indikator turunnya muka air tanah yang diakibatkan oleh pemakaian air tanah yang berlebihan (1).

\subsection{Pengisian Air Tanah}

\subsubsection{Metode Cekungan}

Metode ini dilakukan dengan cara mengisikan air yang berasal dari air sungai atau air hujan ke suatu cekungan tanah atau kolam yang luas yang ada secara alami atau yang dibuat dengan cara pengerukan, sehingga akan terjadi peresapan air ke dalam tanah dalam jumlah yang besar.

Cara ini sangat cocok untuk daerahdaerah yang belum padat oleh pemukiman penduduk dan dapat berfungsi sebagai cadangan air pada saat musim kemarau. Kelemahan dari cara ini adalah kurang baik untuk air yang kandungan lumpurnya besar, karena endapan lumpur yang terjadi dapat menyumbat porositas tanah, sehingga kecepatan peresapan air ke dalam tanah menjadi berkurang.

\subsubsection{Metode Parit}

Di dalam metode ini, air yang berasal dari air hujan atau air sungai didistribusikan ke dalam parit-parit kecil yang dibuat secara sejajar dan tidak terlalu dalam dengan dasar yang rata. Jarak antara parit dibuat tidak terlalu jauh agar didapatkan luas peresapan yang maksimum.

\subsubsection{Metode Saluran Alami}

Metode ini dilakukan dengan cara memanfaatkan aliran-aliran sungai yang ada dengan membuat bendungan-bendungan 
dengan tujuan untuk memperlambat aliran air dan memperpanjang waktu kontak antara air dengan bidang peresapan, sehingga jumlah air yang meresap bertambah besar. Cara ini dapat juga berfungsi sebagai pengontrol banjir dan pengendalian air sungai untuk irigasi.

\subsubsection{Metode Perendaman}

Metode Perendaman yaitu dengan cara menyebarkan air hujan atau air sungai ke permukaan tanah sampai terendam, sehingga meresap ke dalam tanah. Untuk daerah yang datar dan luas, daerah perendaman sering kali menyimpang dari yang direncanakan. Oleh karena itu pada prakteknya, di sekeliling daerah rendaman dibuatkan kanal-kanal atau saluran agar penyebaran dan perendaman air dapat terkendali. Cara ini jarang digunakan karena pengaturannya sulit dan endapan lumpur yang terjadi dapat mengurangi kecepatan peresapan.

\subsubsection{Metode Pengisian Melalui Lubang Galian}

Cara ini digunakan apabila daerah pengisian merupakan daerah berbatu atau daerah yang tanahnya kedap air, sehingga dengan cara penyebaran air ke permukaan tanah kurang efektif. Apabila lapisan tanah kedap air tersebut tidak terlalu tebal, maka peresapan air dapat dilakukan dengan cara menggali lubang atau sumur sampai mencapai lapisan tanah yang lolos air. Air permukaan yang berlebihan, bisa berasal dari air hujan atau air sungai, dimasukkan ke dalam sumuran tersebut, sehingga terjadi peresapan air ke dalam tanah dalam jumlah yang besar. Pada dasar sumur dapat juga diisi dengan kerikil atau koral, yang dapat berfungsi sebagai penyaring endapan lumpur yang terjadi.

Cara ini dapat diterapkan di daerah perladangan, perkebunan atau daerah-daerah yang masih belum padat penduduk. Selain berfungsi untuk peresapan air, juga berfungsi untuk menyimpan air yang berlebihan pada waktu musim hujan. Disamping itu dapat memperlambat aliran air limpasan hujan sehingga dapat mencegah terjadinya banjir.

\subsubsection{Metode Pengisian Melalui Sumur Injeksi}

Sumur injeksi adalah sumur yang digunakan untuk memasukkan atau meresapkan air permukaan ke dalam lapisan tanah (akuifer), baik akuifer tak tertekan maupun akuifer tertekan. Konstruksi sumur kurang lebih sama dengan sumur pompa (pumping well), hanya arah alirannya merupakan kebalikan dari sumur pompa.

Jika air dimasukkan ke dalam sumur injeksi, maka akan terbentuk rembesan air ke dalam tanah yang daerah rembesannya berbentuk kerucut (cone of recharge). Jumlah air persatuan waktu yang dapat diresapkan dalam sumur injeksi ini dapat dihitung dengan rumus sebagai berikut :

Untuk penginjeksian akuifer tak tertekan :

$\boldsymbol{U}_{r}=\frac{K\left(h_{w}\right)}{\ln \left(r_{0}\right)}$

Untuk penginjeksian pada akuifer tertekan :

$\mathrm{Q}_{\mathrm{r}}=\frac{2 \mathrm{~Kb}\left(\mathrm{~h}_{\mathrm{w}}-\mathrm{h}_{0}\right)}{\ln \left(\mathrm{r}_{0}\right)}$

dimana :

$Q_{r} \quad=$ Debit air diresapkan, liter /detik.

$\mathrm{K}=$ Koefisien permeabilitas, $\mathrm{mm} /$ detik .

$\mathrm{h}_{\mathrm{O}}=$ kedalaman air awal, meter

$\mathrm{h}_{\mathrm{W}} \quad=$ kedalaman air akhir, meter.

$r_{\mathrm{W}}=$ Jari-jari kerucut rembesan pada saat operasi pengisian, meter

$r_{0}=$ Jari-jari kerucut pada saat mencapai bidang muka air tanah atau bidang pisometris, meter.

b = Tebal akuifer tertekan, meter.

Dari rumus di atas, baik untuk penginjeksian pada akuifer tertekan maupun tak tertekan, laju peresapan $Q_{r}$, harga koefisien permeabilitas lapisan tanah $(\mathrm{K})$, diameter sumur injeksi $\left(r_{\mathrm{w}}\right)$, tinggi muka air tanah ataupun permukaan pisometris dan juga tinggi air dalam sumur injeksi atau tekanan injeksi (jika memakai pompa). Makin besar harga koefisien permeabilitas $(K)$, diameter sumur $\left(r_{w}\right)$ muka air dalam sumur injeksi (harga $h_{\mathrm{w}}$ makin besar) dan makin rendah muka air tanah ataupun garis pisometris $\left(\mathrm{h}_{\mathrm{o}}\right)$ maka laju peresapan besar. Untuk daerah Jabotabek, harga koefisien permeabilitas (K) bervariasi tergantung dari struktur lapisan tanahnya.

Dari beberapa pengukuran harga $\mathrm{K}$ pada beberapa lokasi di daerah sekitar Jakarta, didapatkan beberapa data seperti tertera pada Tabel 1. Dari data tersebut diketahui bahwa daya peresapan di tiap-tiap tempat bervariasi. Untuk harga $\mathrm{K}=<0,00835 \mathrm{~cm} /$ hari merupakan lapisan yang sulit tertembus oleh air (kedap air). Lapisan ini biasanya terdiri dari lempung halus yang kedap air. 
Untuk harga $\mathrm{K}=0,00835-83,46 \mathrm{~cm} / \mathrm{hari}$ merupakan lapisan akuifer yang terdiri dari pasir halus; lanau (silt); campuran pasir, lanau dan lempung; dan juga lapisan glacial. Sedangkan untuk harga $K=>83,46 \mathrm{~cm} /$ hari merupakan lapisan akuifer yang sangat baik. Lapisan ini biasanya terdiri dari pasir bersih, kerikil atau campuran pasir dan kerikil. Dengan melihat harga koefisien permeabilitas (kelulusan), K, maka dapat diketahui daerah-daerah mana saja yang mempunyai tingkat peresapan yang baik.

Tabel 1. Harga Koefisien Permeabilitas Beberapa Daerah Di Sekitar Jakarta(10,11)

\begin{tabular}{|l|c|c|}
\hline \multicolumn{1}{|c|}{ LOKASI } & $\begin{array}{c}\text { KEDALAMAN } \\
(\mathbf{m})\end{array}$ & $\begin{array}{c}\mathbf{K} \\
(\mathbf{c m} / \mathbf{h a r i})\end{array}$ \\
\hline $\begin{array}{l}\text { PONDOK } \\
\text { GEDE }\end{array}$ & $16,3-17,5$ & 13,40 \\
\hline & $24,5-25,5$ & 64,52 \\
\hline & $25,5-26,5$ & 31,96 \\
\hline & $58,3-60,2$ & 81,56 \\
\hline & $117,5-118,5$ & 22,43 \\
\hline & $30,0-31,0$ & 0,105 \\
\hline & $37,1-41,0$ & 1,897 \\
\hline & $105,0-109,0$ & 0,163 \\
\hline & $137,0-141,0$ & 0,063 \\
\hline & $189,0-193,0$ & 0,74 \\
\hline PARUNG & $57,6-60,0$ & 14,0 \\
\hline & $77,0-79,0$ & 1,68 \\
\hline & $112,0-124,45$ & 1,58 \\
\hline & $184,4-188,4$ & 19,7 \\
\hline & $240,0-244,0$ & 1,18 \\
\hline
\end{tabular}

\subsubsection{Metode Induce Recharge}

Berbeda dengan cara-cara peresapan air buatan seperti yang telah diterangkan diatas, metode ini dilakukan secara tidak langsung dengan cara memompa air tanah dekat aliran sungai, danau atau sumber air permukaan lainnya. Dengan adanya pemompaan air tanah tersebut, muka air tanah akan turun, sehingga dengan adanya penurunan air tanah ini, jumlah air permukaan yang meresap ke dalam tanah menjadi lebih besar.

Dengan cara ini maka air tanah akan mengalami proses mineralisasi yang lebih intensif dari pada air permukaan dan air tanah yang didapat dari hasil pemompaan mengalami penyaringan yang baik selama peresapan.

Dengan metode Induce Recharge, jumlah air yang meresap ke dalam tanah dipengaruhi oleh beberapa hal yaitu :
a) Kecepatan pemompaan atau jumlah air tanah yang diambil.
b) Koefisien permeabilitas (kelulusan tanah), jenis dan kondisi lapisan tanah.
c) Tipe dari sumur pompa.

d) Jarak sumur pompa dengan sumber air permukaan.

e) Arah aliran air tanah secara alami.

\subsection{Penanggulangan Banjir}

Setidaknya ada 4 (empat) upaya yang dapat dilakukan untuk menanggulangi banjir di wilayah Jabodetabek yaitu:

1. Mengoptimalkan Penampungan Air.

2. Penerapan Sumur Resapan.

3. Penataan Lahan yang tepat, Penghijauan.

4. Melakukan evaluasi drainase.

\subsubsection{Penampungan Air}

Penampungan Air seperti waduk dan situ, merupakan alat yang sangat penting dalam rangka mengatur air limpasan yang berasal dari hujan. Sampai saat ini sebagian besar air hujan masih terbuang secara percuma ke laut. Padahal jika musim kemarau datang aliran menjadi kecil, bahkan dibeberapa tempat malah kekurangan air.

Situ-situ di sekitar Jakarta jumlahnya banyak, akan tetapi sebagian sudah mulai beralih fungsi menjadi daerah pertanian dan pemukiman. Situ yang dikelilingi oleh pemukiman jumlah airnya cenderung turun dari tahun ke tahun karena pendangkalan. Di samping itu pemukiman juga mencemari air situ, sehingga kualitasnya menurun. Di Bogor 30\% situ telah berubah fungsi menjadi perumahan. Pengalihan fungsi situ menyebabkan sebagian air yang biasanya tertampung berpindah ke tempat lain, sehingga potensil menyebabkan banjir.

Pengembalian fungsi situ dan waduk akan bermanfaat untuk mengurangi jumlah air yang masuk ke tubuh sungai, sehingga beban sungai menjadi berkurang dan air hujan tidak melimpah ke daerah rawan banjir.

\subsubsection{Sumur Resapan dan Biopori}

Sumur resapan merupakan salah satu cara konservasi air tanah. Caranya dengan membuat bangunan berupa sumur yang berfungsi untuk memasukkan air hujan ke dalam tanah. Tujuan pembuatan sumur resapan yaitu:

a. Melestarikan dan memperbaiki kualitas lingkungan.

b. Membantu menanggulangi kekurangan air bersih.

c. Membudayakan kesadaran lingkungan.

d. Mengurangi erosi tanah.

Keuntungan yang dapat diperoleh jika melakukan konservasi dengan menggunakan sumur resapan adalah (19):

a. Mencegah intrusi air laut terutama di dataran pantai. 
b. Mereduksi dimensi jaringan drainase (dapat sampai nol jika diperlukan).

c. Menurunkan konsentrasi pencemaran air tanah.

d. Mempertahankan tinggi muka air tanah.

e. Mencegah penurunan kawasan atau land subsiden.

f. Melestarikan teknologi tradisionil sebagai budaya bangsa.

g. Meningkatkan peran serta masyarakat dalam era pembangunan.

h. Membudayakan pola pikir pelestarian lingkungan.

Untuk membangun suatu sumur resapan agar dapat memberikan kontribusi yang optimum diperlukan metoda perhitungan sebagai berikut:

1. Menghitung debit masuk sebagai fungsi karakteristik luas atap bangunan dengan formula rasional $(\mathrm{Q}=\mathrm{CIA}, \mathrm{Q}=$ debit masuk, $\mathrm{C}=$ Koefisien Aliran(jenis atap), I=Intensitas Hujan, $A=$ Luas atap).

2. Menghitung kedalaman sumur optimum, yang diformulakan sebagai berikut ${ }^{(19)}$ :

$$
H=\frac{Q}{F K}\left[1-e^{-\left(\frac{F K T}{\pi R^{2}}\right)}\right]
$$

$$
\begin{aligned}
& \text { Keterangan: } \\
& H=\text { Kedalaman air }(\mathrm{m}) \\
& \mathrm{Q}=\text { Debit masuk }(\mathrm{m} 3 / \mathrm{dt}) \\
& \mathrm{F}=\text { Faktor geometrik }(\mathrm{m}) \\
& \mathrm{K}=\text { Permeabilitas tanah }(\mathrm{m} / \mathrm{dt}) \\
& \mathrm{R}=\text { Radius sumur }(\mathrm{m}) \\
& \mathrm{T}=\text { Durasi aliran }(\mathrm{dt})
\end{aligned}
$$

3. Evaluasi jenis fungsi dan pola letak sumur pada jarak saling pengaruh guna menentukan kedalaman terkoreksi dengan menggunakan "multi well system".

Biopori saat ini juga banyak dikembangkan. Biopori adalah pembuatan lubang sedalam $50-100 \mathrm{~cm}$, dengan menggunakan peralatan pembuat lubang berdiameter $15 \mathrm{~cm}$. Lubang tersebut diisi serasah dedaunan atau sampah organik yang berasal dari daerah sekitarnya. Pembusukan dari bahan organik akan menumbuhkan organisme cacing dan membentuk rongga yang banyak di dalam dinding lubang. Semakin banyak lubang yang terbentuk akan semakin porous lubang bioporinya.

\subsubsection{Penataan Penggunaan Lahan, Terasering, bangunan Penahan Air dan Penghijauan}

Hujan yang jatuh ke bumi sebagian mengalir sebagai air permukaan, sebagian meresap dan sebagian menguap. Penggunaan lahan berpengaruh pada koefisien limpasan.
Penutupan lahan oleh bangunan kedap air akan memperbesar air limpasan karena air yang seharusnya meresap kedalam tanah berubah menjadi air limpasan.

Perubahan penggunaan lahan dari perkebunan menjadi pemukiman akan mengakibatkan perubahan besar pada jumlah air limpasan. Pembuatan terasering bermanfaat untuk menahan laju erosi dengan membuat topografi menjadi datar. Dengan demikian air akan mengalir lebih lambat. dan lebih banyak yang meresap dalam tanah. Bangunan penahan air berfungsi sebagai penahan laju sedimen dan banjir.

\subsubsection{Evaluasi Drainase}

Tujuan dari dilakukannya evaluasi drainase adalah untuk mengetahui kemampuan saluran drainase mengalirkan air sungai agar tidak terjadi penggenangan. Untuk dapat melakukan evaluasi drainase maka harus dilakukan penghitungan terhadap banjir rencana yang disebabkan oleh hujan yang terjadi dengan periode ulang tertentu, misalnya periode ulang 1 sampai 100 tahun di Jakarta. Berdasarkan hasil perhitungan tersebut maka rencana bangunan air seperti lebar kapasitas saluran drainase dapat dihitung, sehingga jika terjadi hujan dengan periode ulang tertentu, maka air yang akan di alirkan tidak akan melimpah keluar. Sebagai akibatnya, maka tidak akan melimpah keluar saluran dan menggenangi daerah rawan banjir.

Untuk mengatasi banjir khususnya untuk DKI Jakarta, secara prinsip dapat dilakukan dengan cara: pertama adalah memperkecil jumlah air limpasan yang masuk ke sungai, yakni misalnya menata kawasan hulu, mempertahankan atau menambah kawasan hijau/terbuka, memelihara dan bila mungkin menambah jumlah situ/waduk, membuat sumur resapan, penghijauan daerah tangkapan air hujan, pembuatan cek dam di daerah hulu dan lain-lain. Kedua yakni dengan cara memperbesar kapasitas sistem drainase, yakni dengan cara memperlebar atau memperdalam sungai/saluran, pembuatan saluran/kanal banjir, pengembangan sistem polder dan pompanisasi, rehabiltasi jembatan, dan lain-lain

\section{PAH DAN SURES DI INDONESIA}

PAH di Indonesia banyak di bangun di wilayah pesisir dan pulau-pulau kecil yang langka air tawar. Di Wilayah transmigrasi yang langka air, seperti di Kalimantan Tengah, Lampung Timur, setiap rumah mendapat bantuan penampung air hujan dengan volume $500-1000$ liter. Ada juga penampung yang di bangun di kantor desa atau kelurahan dan terbuat dari besi 
atau fibre dengan volume 5 - $10 \mathrm{~m}^{3}$. Umumnya diletakkan dipermukaan tanah, sehingga mudah dalam pemanfaatannya. Kelemahannya umumnya terdapat pada perawatan pembersihan bagian dalamnya dan keran-keran yang sering bocor tidak diperbaiki. PAH sangat bermanfaat untuk pulau-pulau kecil dan daerah pesisir, karena murah dan praktis.

Untuk wilayah Jakarta dan sekitarnya berdasarkan hasil studi yang dilakukan oleh BPPT $(13,14)$ dalam Studi-studi Model Optimisasi Pengelolaan Air Tanah Jakarta, maka besarnya imbuhan buatan yang harus dimasukkan kembali ke dalam akuifer dangkal untuk daerah seluas $25 \mathrm{~km}^{2}$ berkisar antara 1.082.419- 54.120.960 $\mathrm{m}^{3} /$ tahun atau antara $1,08-54,12 \mathrm{~m}^{3} /$ tahun $/ \mathrm{m}^{2}$. Lokasi imbuhan buatan dapat dilihat pada Peta Lokasi Imbuhan Buatan Berdasarkan Hasil Optimisasi Pengelolaan Air Tanah. Jika diasumsikan 1 (satu) sumur resapan dengan diameter 0,8 meter, lebar bidang resapan $1 \mathrm{~m}$ pada tanah dengan permeabilitas rendah $(0,00105 \mathrm{~m} /$ hari $)$, maka kapasitas sumur resapan adalah 0,592 $\mathrm{m}^{3} /$ tahun/unit. Dengan demikian untuk daerah Jakarta dan sekitarnya dibutuhkan kurang lebih 2 juta sumur resapan.

DKI Jakarta dan pemerintah daerah sekitarnya, telah membangun ribuan sumur resapan. Harapan dari pembangunan tersebut adalah masyarakat mencontoh, sehingga replikasinya dapat berjalan lebih cepat, dan dampaknya dapat dirasakan bersama. Pemda DKI juga sudah membuat Perda Nomor 68 Tahun 2005 tentang Pembuatan Sumur Resapan dan brosur(15). Sosialisasi sumur resapan masih perlu ditingkatkan dan dilakukan terus menerus.

\section{HASIL DAN ANALISIS}

Penampungan Air Hujan ini didesain dengan volume $10 \mathrm{~m}^{3}$, serta dilengkapi dengan sistem penyaringan yang berupa saringan pasir dan kerikil dan flotasi. Sistem penyaringan ini diharapkan mampu menyaring daun-daun, debu atau pasir yang jatuh di atap, sehingga tidak masuk ke dalam PAH. Jika hujan yang turun cukup lebat, maka PAH sudah penuh dan airnya akan mengalir ke dalam sumur resapan.

$\mathrm{PAH}$ konstruksinya terbuat dari beton, bentuk kotak, panjang $500 \mathrm{~cm}$, dalam $235 \mathrm{~cm}$ dan lebar $110 \mathrm{~cm}$ dilengkapi dengan pompa dan filter untuk pemanfaatan air yang telah ditampung. Air yang sudah tertampung ke dalam tangki PAH dapat dimanfaatkan sebagai air bersih yang dapat digunakan untuk keperluan mandi, cuci, kakus (MCK). Untuk itu dilengkapi dengan pompa sedot, filter dan kontrol panel. Kontrol panel berfungsi untuk mengatur jalannya pompa, memberikan tanda kepada operator apakah dalam tangki PAH ada air atau kosong.
Indikasi adanya air dalam tangki $\mathrm{PAH}$ ditandai dengan lampu yang menyala hijau.

Pengukuran terhadap kapasitas infiltrasi dilakukan di tiga lokasi dengan melakukan pengukuran menggunakan ring infiltrasi. Pengukuran langsung di sumur resapan dengan mengandalkan hujan yang jatuh di lokasi. Kemudian melakukan pengetesan secara langsung laju infiltrasi dengan menggunakan air bersih yang diperoleh dari penyedia jasa air bersih (PAM atau Tangki Air Baku Isi ulang) dengan menggunakan mobil tangki air bersih (20).

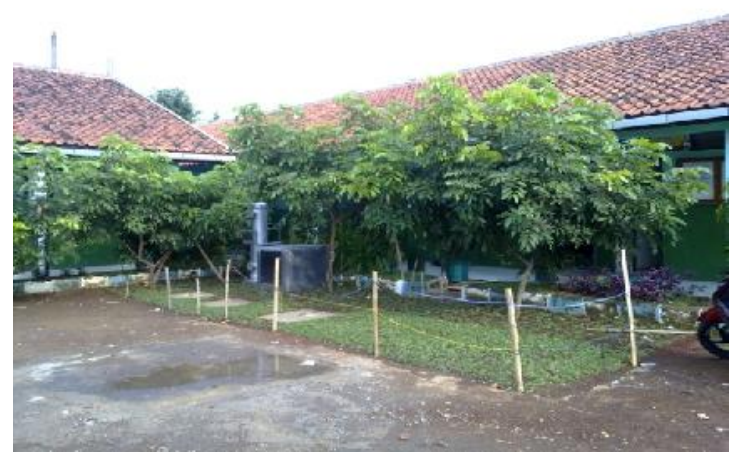

Gambar 4. Contoh PAH Kapasitas $10 \mathrm{~m}^{3}$ di Bantarjati, Bogor

Pengukuran terhadap kapasitas infiltrasi dilakukan di tiga lokasi dengan melakukan pengukuran menggunakan ring infiltrasi. Pengukuran langsung di sumur resapan dengan mengandalkan hujan yang jatuh di lokasi. Kemudian melakukan pengetesan secara langsung laju infiltrasi dengan menggunakan air bersih yang diperoleh dari penyedia jasa air bersih (PAM atau Tangki Air Baku Isi ulang) dengan menggunakan mobil tangki air bersih.

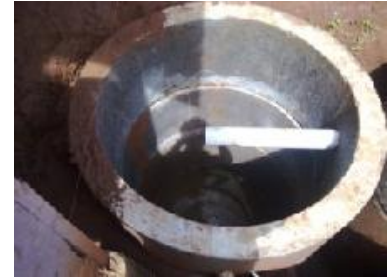

(a)

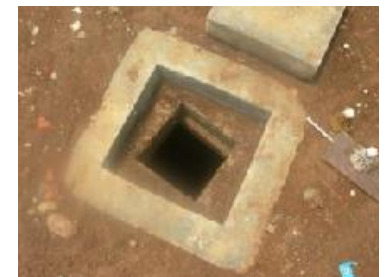

(b)
Gambar 5. Sumur Resapan Yang Masih Terbuka (a) Dan Yang Sudah Tertutup (b)

Pengukuran terhadap penurunan air meresap, baik yang dilakukan dengan menggunakan ring-infiltrometer maupun di dalam sumur resapan dilakukan setiap interval 5 (lima) menit. Hasil penurunan tinggi muka air dicatat di setiap interval waktu. Jika permukaan air yang akan diukur telah mendekati permukaan tanah, maka tambahkan air ke dalam ring infiltrometer 
atau sumur resapan. Hal ini dilakukan untuk mempermudah pencatatan. Pengukuran dilakukan terus dan dihentikan setelah kontinuitas penurunan mencapai konstan atau stabil.

Hasil Pengujian di SD 1,2,3 dan 4, Bantarjati, Bogor adalah sebagai berikut : Volume PAH adalah $10 \mathrm{~m}^{3}$, dapat penuh dalam waktu $1-2$ kali hujan dengan intensitas sedang (15 - $20 \mathrm{~mm} / \mathrm{jam})$, Pompa Air untuk pemanfaatan air PAH mempunyai kapasitas 25 - 30 liter/menit, air dapat digunakan untuk keperluan MCK dan siram-siram tanaman. Hasil pengujian peresapan menunjukkan kemampuan inlfiltrasi sumur resapan adalah tertinggi sekitar 45 $\mathrm{mm} / \mathrm{menit}$ dan relatif stabil (steady) pada menit ke 260 (2,5 mm/ menit). Satu Sumur Resapan mampu meresapkan air 1000 liter dalam waktu 150 menit.

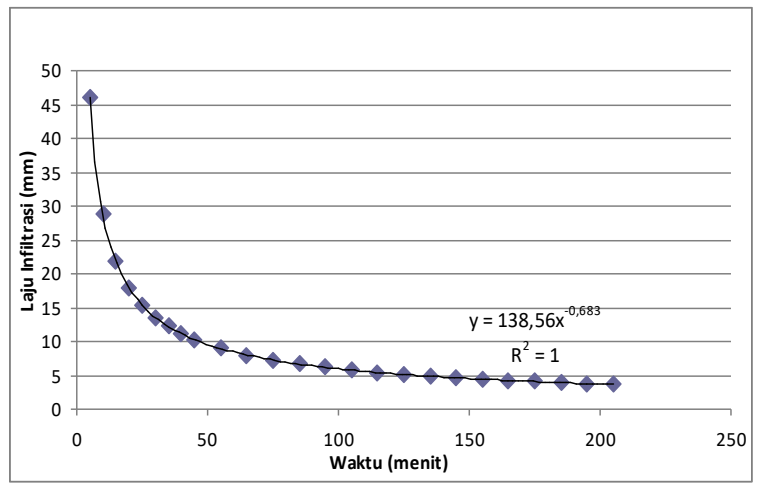

Gambar 6. Laju Infiltrasi Sumur Resapan di SDN Kawung Luwuk, Kelurahan Bantarjati, Bogor Utara

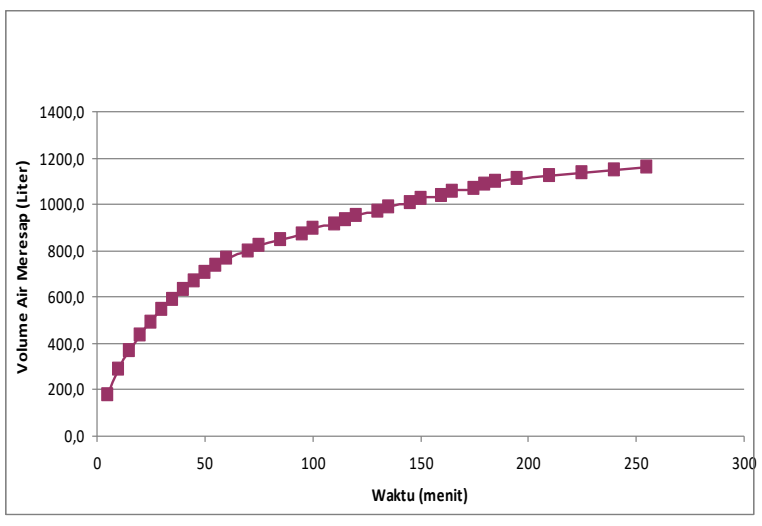

Gambar 7. Volume Kumulatif Air Resapan di Satu Sumur Resapan SDN Kawung Luwuk, Kelurahan Bantarjati, Bogor Utara

Hasil analisis dengan metode perhitungan Kostiokov terhadap laju infiltrasi di lahan disekitar sumur resapan dan Laju volume peresapan pada Sumur resapan, dapat pada Gambar 6 s/d 11, sedangkan resumenya dapat dilihat pada Tabel
2. Hasil Pengujian di SMA 4 Depok, adalah sebagai berikut: Volume Penampungan Air Hujan (PAH) adalah $10 \mathrm{~m}^{3}$, dapat penuh dalam waktu $1-2$ kali hujan dengan intensitas sedang (15 - $20 \mathrm{~mm} / \mathrm{jam})$, Pompa Air untuk pemanfaatan air PAH mempunyai kasistas 25 - 30 liter/menit, air dapat digunakan untuk keperluan MCK dan siram-siram tanaman.

Hasil pengujian peresapan menunjukkan kemampuan infiltrasi sumur resapan adalah tertinggi sekitar $12 \mathrm{~mm} / \mathrm{menit}$ dan rekatif stabil (stedy) pada menit ke 140 (2 mm/menit). Satu Sumur Resapan mampu meresapkan air 450 liter dalam waktu 140 menit.

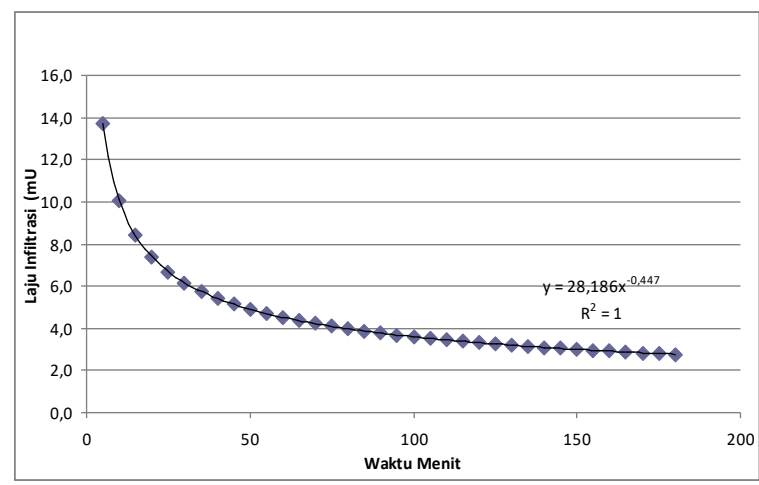

Gambar 8. Perkembangan Laju Infiltrasi Pada Sumur Resapan di SMA 4, Depok

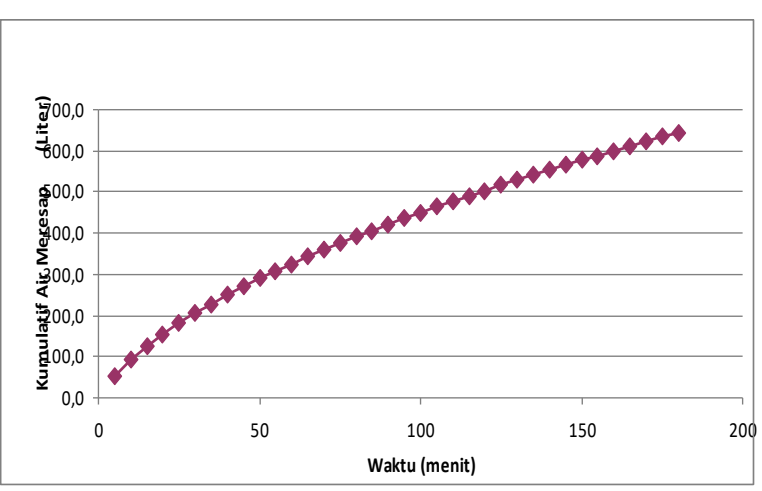

Gambar 9. Kumulatif infiltrasi air yang meresap ke dalam sumur resapan di SMA 4, Depok

Hasil Pengujian di SMA Al Azhar, Jakarta, adalah sebagai berikut : Volume $\mathrm{PAH}$ adalah $10 \mathrm{~m}^{3}$, dapat penuh dalam waktu $1-2$ kali hujan dengan intensitas sedang (15 - 20 $\mathrm{mm} / \mathrm{jam})$, Pompa Air untuk pemanfaatan air PAH mempunyai kasistas 25 - 30 liter/menit, air dapat digunakan untuk keperluan MCK dan siram-siram tanaman. Hasil pengujian peresapan menunjukkan kemampuan infiltrasi sumur resapan adalah tertinggi sekitar $11 \mathrm{~mm} /$ menit dan relatif stabil (steady) pada menit ke $160(2,5 \mathrm{~mm} /$ menit). Satu Sumur Resapan mampu meresapkan air 480 liter dalam waktu 160 menit. 


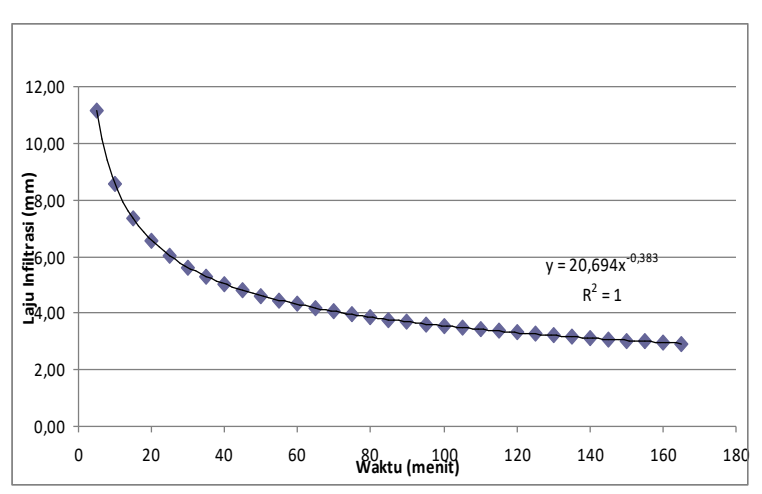

Gambar 10. Laju Infiltrasi Sumur Resapan di SMA AL-Azhar, Jakarta Timur

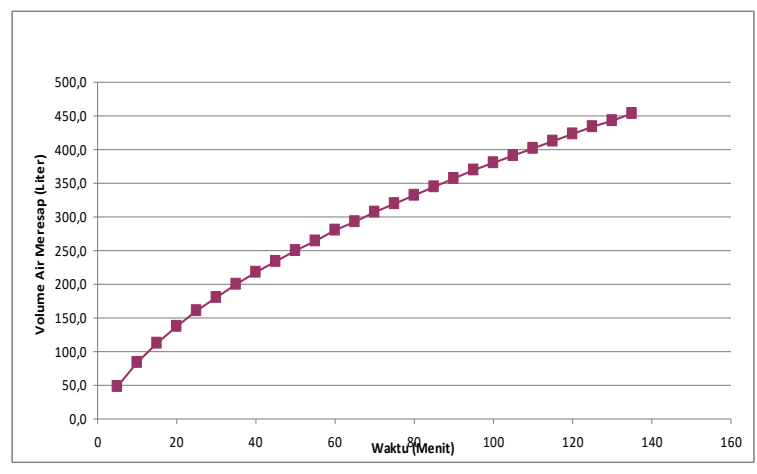

Gambar 11 Volume Kumulatif Air Resapan Yang Masuk Ke Dalam Satu Sumur Resapan di SMA Al Azhar, Jakarta Timur

Tabel 2. Hasil Analisis Sumur Resapan Dan Percobaan Laju Infiltrasi Di Lokasi Penelitian

\begin{tabular}{|c|l|l|c|c|}
\hline No & $\begin{array}{c}\text { Lokasi } \\
\text { Penelitian }\end{array}$ & Metode & $\begin{array}{c}\text { Laju } \\
\text { Infiltrasi } \\
\mathrm{mm} / \mathrm{mnt}\end{array}$ & $\begin{array}{c}\text { Laju } \\
\text { Volume } \\
\text { (Itr/mnt) }\end{array}$ \\
\hline $\mathbf{2}$ & $\begin{array}{l}\text { SD N } \\
\text { Kawung } \\
\text { Luwuk Bogor }\end{array}$ & $\begin{array}{l}\text { Ring } \\
\text { Infiltrometer }\end{array}$ & 1,3 & - \\
\hline 3 & $\begin{array}{l}\text { SD N } \\
\text { Kawung } \\
\text { Luwuk Bogor }\end{array}$ & $\begin{array}{l}\text { Sumur } \\
\text { Resapan 1 }\end{array}$ & 2,9 & 2,28 \\
\hline 4 & $\begin{array}{l}\text { SD N } \\
\text { Kawung } \\
\text { Luwuk Bogor }\end{array}$ & $\begin{array}{l}\text { Sumur } \\
\text { Resapan 2 }\end{array}$ & 3,6 & 2,83 \\
\hline 5 & $\begin{array}{l}\text { SMA N4 } \\
\text { Depok (Air } \\
\text { hujan) }\end{array}$ & $\begin{array}{l}\text { Sumur } \\
\text { Resapan } \\
\text { Perc-1 }\end{array}$ & 2,4 & 1,88 \\
\hline 6 & $\begin{array}{l}\text { SMA N4 } \\
\text { Depok (Air } \\
\text { Bersih- } \\
\text { Tangki Air) }\end{array}$ & $\begin{array}{l}\text { Sumur } \\
\text { Resapan } \\
\text { Perc-2 }\end{array}$ & 2,7 & 2,12 \\
\hline $\begin{array}{l}\text { Sekolah Al- } \\
\text { Azhar (Air } \\
\text { Hujan) }\end{array}$ & $\begin{array}{l}\text { Sumur } \\
\text { Resapan } \\
\text { Perc-1 }\end{array}$ & 2,9 & 2,28 \\
\hline
\end{tabular}

\section{MANFAAT PAH DAN SURES}

Adanya pembangunan PAH dan SURES di halaman sekolah, baik di Bantarjati, Bogor, SMAN 4 Depok dan SMA Al Azhar, Jaksel, terlihat bahwa halaman sekolah sekitarnya menjadi tidak tergenang air dan air yang tertampung dalam $\mathrm{PAH}$ dapat dimanfaatkan untuk keperluan MCK, kebersihan teras sekolah dan penyiraman tanaman di halaman sekolah (Gambar 12).

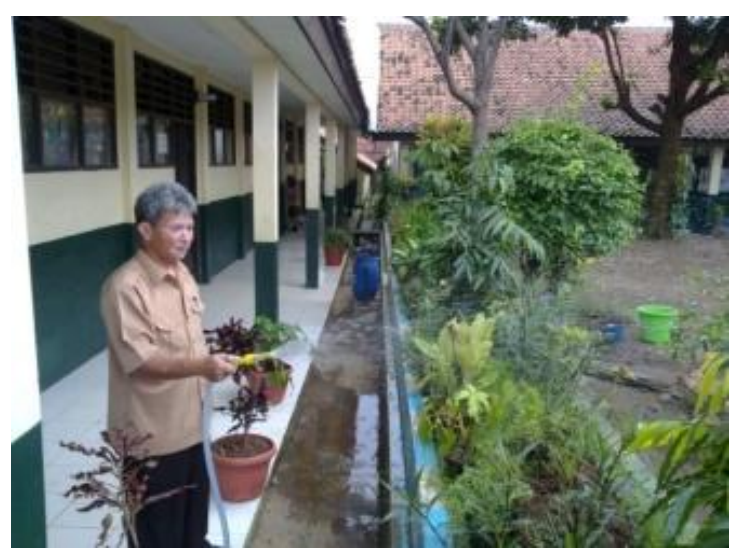

Gambar 12. Pemanfaatan PAH Untuk Siram Tanaman Di Sekitar Sekolah

\section{KESIMPULAN}

1. Secara umum PAH dan SURES yang dibangun bermanfaat untuk menurunkan laju aliran permukaan dan airnya dapat dimanfaatkan untuk keperluan MCK, cuci tangan para murid, kebersihan sekolah, dan penyiraman tanaman, penghematan penggunaan air PDAM serta menjadi media pendidikan yang efektif untuk para murid dengan harapan akan terjadi diseminasi teknologi secara mandiri oleh masyarakat.

2. Bangunan dengan luas atap $375 \mathrm{~m}^{3}$ mampu mengisi penuh $\mathrm{PAH}$ dengan volume $10 \mathrm{~m}^{3}$, dengan curah hujan $20 \mathrm{~mm} / \mathrm{jam}$, dengan asumsi durasi hujan 3 jam dan koefisien run off 0,9. Bangunan sekolah tersisa masih sangat luas, potensi air hujan yang bisa ditampung sangat banyak, tergantung kebutuhan. Pengalaman di negara yang sudah memanfaatkan air hujan untuk keperluan gedung, kebutuhan airnya dapat dipenuhi dari air hujan sampai $35-45 \%$.

3. Hasil pengujian karakterisasi SURES yang dilakukan menunjukkan kemampuan infiltrasi sumur resapan adalah tertinggi sekitar $45-11$ $\mathrm{mm} /$ menit dan relatif stabil (steady) pada menit ke 140- 260 - (2,5 mm/menit). Satu Sumur Resapan mampu meresapkan air secara kumulatif 450 - 1000 liter dalam waktu 140 - 160 menit. 


\section{SARAN - SARAN}

1. Perlu diadakan sosialisasi secara intensif dan melibatkan sebanyak mungkin unsur pemerintah, swasta dan masyarakat.

2. Di setiap gedung perkantoran dan gedunggedung yang mengokupasi lahan dan dengan tutupan lahan yang menghalangi meresapnya air ke dalam tanah diwajibkan membuat sumur resapan yang dilengkapi dengan pemanenan air hujan.

3. Program konservasi air tanah pada khususnya dan konservasi sumberdaya air pada umumnya perlu dijadikan bagian dari kurikulum di sekolah dari seluruh tingkatan agar setiap murid dapat memahami perlunya mengelola sumberdaya air sesuai dengan tingkatan kemampuannya. Dengan demikian pada gilirannya, pengetahuan ini akan dibawa ke lingkungan sekitar tempat tinggalnya dan diharapkan berbuat sesuatu untuk mengkonservasi sumberdaya air

\section{DAFTAR PUSTAKA}

1. Anonim-1.2000. Studi Pengaruh Pemompaan Air Bawah Tanah Terhadap Land Subsidence dan Intrusi Air Laut, Dinas Pertambangan DKI Jakarta.

2. Anonim-2.1983. Masterplan for Jakarta water supply development project. Interim Report. Desember 1983. JICA. Jakarta.

3. Anonim-3.2001. Keputusan Gubernur Propinsi DKI Jakarta Nomor 115 Tahun 2001 tentang Pembuatan Sumur Resapan, Pemerintah DKI Jakarta.

4. Anonim-4.2005, Keputusan Gubernur Propinsi DKI Jakarta Nomor 68 Tahun 2005 Perubahan Keputusan Gubernur Provinsi DKI Jakarta Nomor 115 Tahun 2001 Tentang Pembuatan Sumur Resapan

5. Anonim-5.1994. Jabotabek Water Resources Management Study. Directorate General of Water Resources Development. Ministry of Public Works. Government of Indonesia. IWACO, DHV Consultants, DELFT HYDRAULICS, TNO, PT. Indah Karya, PT. Kwarsa Hexagon, PT. Wiratman \& Associates. Jakarta.

6. Anonim-6.2004. Undang - Undang Republik Indonesia Nomor 7 tahun 2004 tentang Sumberdaya Air.

7. Anonim-7.1996. Peta Geologi Tata Lingkungan Indonesia. Lembar: DKI Jakarta. Direktorat Geologi Tata Lingkungan. Bandung.

8. Anonim-8.2004. Potret Jakarta; Kondisi Air Bawah Tanah. Lokakarya "Perubahan Iklim dan Implikasi terhadap Bencana Alam Di DKI
Jakarta; Antisipasi dan Mitigasi Dampak Kemarau - Banjir". Dinas Pertambangan DKI. Jakarta. 24 - 25 Maret 2004.

9. Anonim-10.1995. Peta Hidrogeologi Indonesia. Lembar 1209-1. Bogor. Jawabarat. Disalin dari : Laporan Tahunan DGTL, 1994/1995. Direktorat Geologi Tata Lingkungan

10. Anonim-12.1987. Cisadane River basin development feasibility study. Final feasibility report. Main report. Vol.1. Indec \& Associates Ltd. Jakarta. Indonesia

11. Anonim-13.1987. Cisadane River Basin Development Feasibility Study. Final Feasibility Report. Groundwater. Vol.3. Indec \& Associates Ltd Jakarta. Indonesia.

12. Arsyad, S.2006. Konservasi Tanah dan Air.IPB Press. Bogor

13. Haryoto, I, dkk.1992. Optimisasi, Studi Model Optimisasi Pengelolaan Air Tanah Jakarta. Jakarta. Direktorat Pengkajian Sistem, Kedeputian Bidang Analisis Sistem, Badan Pengkajian dan Penerapan Teknologi.

14. Herlambang, Arie, dkk.1991. Simulasi dan Kalibrasi, Studi Model Optimisasi Pengelolaan Air Tanah Jakarta. Jakarta. Direktorat Pengkajian Sistem, Kedeputian Bidang Analisis Sistem, Badan Pengkajian dan Penerapan Teknologi.

15. Pemerintah Daerah Khusus Ibukota Jakarta, Brosur, Sumur Resapan Buatan Air Hujan. Jakarta. Dinas Pertambangan DKI.

16. Samsuhadi.2009. Pemanfaatan Air Tanah Jakarta. Jurnal Air Indonesia. Vol 5. No 1. Juni 2009. Pusat Teknologi Lingkungan. Deputi TPSA. BPPT. Jakarta

17. Sunjoto.1992. Brosur Sistem Drainase Air Hujan Berwawasan Lingkungan. Yogyakarta. Fakultas Teknik Universitas Gadjah Mada.

18. Todd,D.K.1980. Groundwater Hydrology, Second Edition, John Wiley \& Sons, NY.

19. Kamis R.B. dkk, 2011, Resapkan Air Hujan Menjadi Air Tanah, http://www.biopori.com.

20. Laporan Akhir 2011, Pembangunan Teknologi Kombinasi Pemanenan Air Hujan dan Sumur Resapan, BPPT-RISTEK, 2011. 